DOI : https://amj.journals.ekb.eg/article_64946.html

https://amj.journals.ekb.eg/article_64947.html

\title{
SUICIDALILTY IN A SAMPLE OF EGYPTIAN ADOLESCENTS WITH SUBSTANCE USE DISORDER
}

\author{
By
Ali Ismail Abd El-Rahman, Abdullah Ahmed Abdullah Mekki, Ismail Mohamed Sadek and Mahmoud Osama Abd El-Hady Yousef* \\ Department of Psychiatry, Faculty of Medicine, Al-Azhar University, Cairo, Egypt \\ *Corresponding author: Mahmoud Osama Abd El-Hady Yousef,
}

Mobile: 01022698221

E-mail: mahmoudosama1989@gmail.com

\begin{abstract}
Background: Suicide is classified as the highest cause of death among young people compared to other age groups and is the second leading cause of death during childhood and adolescence. many people who have attempted suicide in their lives during their youth, the beginning of thinking about suicide and attempted suicide usually occurs before the mid-twenties. Substance use disorder and suicide usually occur among adolescents. In young people receiving treatment for substance use, $18 \%$ to $36 \%$ report a history of patients with suicidal behavior. Furthermore, adolescents diagnosed with substance use disorder were 5 to 13 times more likely to die from suicide than adolescents without this diagnosis.
\end{abstract}

Objective: To find the association of suicidality among adolescents and substance use disorder.

Patients and Methods: The sample consisted of 50 adolescent diagnosed with substance use disorder and 50 adolescent diagnosed with other psychiatric disorder not included substance use disorder and their age were range from 12 to 18 years old. After diagnosed clinically, according to DSM-5 through a designed semi structured interview and through application of Mini International Neuropsychiatric Interview for children and adolescents, suicidal probability scale, teen addiction severity index, and Questionnaire of parental attitudes.

Results: there was a direct relationship between of addiction and susceptibility to suicide. It was found that there were statistically significant differences between the control and sample groups in terms of family history of addiction. It was found that $68 \%$ of the sample cases have a family history of addiction compared to $26 \%$ of the control and found that $32 \%$ of the sample cases have no family history of addiction compared to $74 \%$ of control. There were statistically significant differences in the sample for a major depressive episode, dysthymia, post-traumatic stress disorder, attention deficit hyperactivity disorder and generalized anxiety disorder. For the control, there were statistically significant differences for a particular phobia. There was a relationship between substance used disorder and comorbidity of psychiatric disorder.

Conclusion: The results of the study showed that there was a relationship between the severity of addiction and susceptibility to suicide and that there were many psychiatric disorders associated with substance use disorder.

Key words: Substance use disorder - suicide - adolescents. 


\section{INTRODUCTION}

Adolescence is a time of transition involving multi-dimensional changes: biological, psychological (including cognitive) and social. Biologically, adolescents are experiencing pubertal changes, changes in brain structure and sexual interest, as a start. Psychologically, adolescents' cognitive capacities are maturing. They are experiencing social changes through school and other transitions and roles they are assumed to play in family, community and school (Scherf et al., 2012). During adolescence, many unhealthy behaviors often begin and pose significant public health challenges. Substance used disorder has a significant impact on individuals, families and communities, as its effects are cumulative, contributing to increased health and social problems and severely affecting mental health (Jobes., 2016).

The nature of the relationship between mental disorders and substance used disorder is complex and multifaceted. Evidence suggests that negative emotional states and stress related to the urge to take drugs create an emotional disturbance for individuals who use drugs. A change in policy levels will be necessary to make the most of vital neurological explorations so that these results can be used to improve the lives of individuals with comorbidity (Hartwell et al., 2009).

Many people who have attempted suicide in their lives did so during their youth, as the shelf life of the beginning of thinking about suicide and attempted suicide usually occurs before the mid-twenties (Christine et al., 2017). Substance used disorder and suicide usually occurs among adolescents. In young people receiving treatment for substance use, $18 \%$ to $36 \%$ report a history of patients with suicidal behavior. It is noted that the presence of a suicidal behavior is associated with an increase of 3 to 4 times in suicide attempts. Furthermore, adolescents diagnosed with substance use disorder were 5 to 13 times more likely to die from suicide than adolescents without this diagnosis (Glenn et al., 2015).

A cute effects of alcohol may be risk factors close to suicidal behavior by increasing psychological stress, aggression, cognitive distortion and by reducing the ability to solve problems. With alcohol-induced stress, adolescents considering suicide may be more likely to overcome these thoughts. This may help explain why a large proportion of adolescents, especially those seeking to treat substance use disorders, who used alcohol or other substances before attempting suicide, have a reason. The use of the substance as a risk factor away from suicidal behavior can also result in a negative impact on the adolescent environment, increased stress, and the negative impact of stress it was found that adolescents who suffer from severe psychological pressures associated with substance use, many resort to escape these stresses during suicide (Glenn et al., 2015). 
The present work aimed to study the clinical presentation of the adolescent substance use disorders, including the patterns and the severity of abuse. And to find the association of suicidality and substance use disorder among adolescents who, attended to Helwan Mental Health Hospital during the period from May 2018 to April 2019.

\section{PATIENTS AND METHODS}

This study was conducted at Helwan Mental Health Hospital (adolescent unit) where 50 adolescent diagnosed with substance used disorder and 50 adolescent diagnosed with other psychiatric disorder not including substance used disorder, were chosen randomly during the period between May 2018 to April 2019 to seek medical help and to complain about some changes in their life and study problems and their age ranged between 12 and 18 years old. Tools were used is Mini International Neuropsychiatric Interview for Children and Adolescents(MINI-KID) Arabic version (Sheehan et al.,1990) Arabic version (Awaad et al., 2002), Suicidal Probability Scale (Gull and Gill., 1982) Arabic version (Albehairy., 2013), Teen Addiction Severity Index (Kaminer et al .,1991) and Questionnaire of parental attitudes (Abd El-Maksood A.,1995). Used tools were standardized. All patients signed informed written consents after explanation of the aim of the study and its details

\section{Inclusion criteria included}

The age range was 12-18years, both sexes were included, according to case groyp diagnosed as substance use disorder according to control group patients diagnosed as other psychiatric disorder by the previously mentioned tools .

\section{Exclusion criteria included}

Patients with medical co-morbidity or neurological disorders

\section{Ethical and approval considerations:}

Oral and written consent was taken from patients taking into considerations maintaining the confidentiality of the data, and approval of Training Department of the General Secretariat of Mental Health to do the research.

\section{Statistical analysis:}

All data were collected and analyzed using SPSS program 25 edition using ttest $\mathrm{p}$-value was considered significant > 0.05 and Pearson's correlation coefficient was also used. 


\section{RESULTS}

During the description of the sample in terms of the type of substances abuse, it was found that the use of synthetic cannabis (strokes or Voodoo) was $84 \%$, the use of cannabis was $72 \%$, the proportion of abuse of tramadol was $40 \%$, the proportion of abuse of benzo derivatives was $26 \%$, the proportion of abuse of opiates was $6 \%$ and that alcohol consumption was $50 \%$. Use of other substances such as benzene derivatives, glue and cough drugs was $10 \%$, and the tobacco smoking in the sample was $100 \%$ (Table 1).

Table (1): Distribution of the studied patients according to type of substance abuse

\begin{tabular}{|l|l|l|}
\hline Substance & N =50 & \% \\
\hline Main substance: & & \\
Synthetic drug (e.g. strokes-vodo) & 42 & 84 \\
Hashish & 36 & 72 \\
\hline Tramadol & 20 & 40 \\
Benzo derivative & 13 & 26 \\
Heroin & 3 & 6 \\
Alcohol & 25 & 50 \\
Others & 5 & 10 \\
Tobacoo & 50 & 100 \\
\hline
\end{tabular}

According to suicide probability scale, mean of hoplesness cases was 32.28 while the control was 32.54. Mean of suicidal ideation was 26.14 while that of control 26.86. Mean of negative self- evaluation was 16.62 and that of control war 17.32 . The hostility was 20.50 , while control was 21.60 and the total in the case 95.54,while control was 98.32 (Table 2).

Table (2): Distribution of the studied patients according to Suicide probability scale

\begin{tabular}{|l|l|l|l|l|l|}
\hline Groups & mean & SD & mean & SD & $\begin{array}{l}\text { p- } \\
\text { value }\end{array}$ \\
\hline Hopelessness & 32.54 & 7.53 & 32.28 & 8.64 & 0.873 \\
\hline Suicidal ideation & 26.86 & 5.32 & 26.14 & 7.15 & 0.569 \\
\hline Negative self-evaluation & 17.32 & 1.97 & 16.62 & 2.49 & 0.119 \\
\hline Hostility & 21.60 & 4.77 & 20.50 & 5.03 & 0.265 \\
\hline Total & 98.32 & 14.36 & 95.54 & 17.02 & 0.379 \\
\hline
\end{tabular}

There was a direct relationship between the severity of addiction and the probability of suicide, and there was an inverse relationship between the severity of addiction and negative self-evaluation (Table 3). 
SUICIDALILTY IN A SAMPLE OF EGYPTIAN ADOLESCENTS WITH...

401

Table (3): the relation between suicidality and severity of addiction

\begin{tabular}{|l|l|l|}
\hline & P-value & Pearson coefficient \\
\hline Hopelessness & 0.080 & 0.250 \\
\hline Suicidal ideation & 0.001 & $0.465^{* *}$ \\
\hline Negative self-evaluation & 0.009 & $-0.364^{* *}$ \\
\hline Hostility & 0.042 & $0.288^{*}$ \\
\hline Total & 0.011 & $0.355^{*}$ \\
\hline
\end{tabular}

\section{DISCUSSION}

By comparison of case and control according to gender was found 38 people were males and 12 war females, while the control was 36 males and 14 females had substance use disorder. Jain et al. (2016) stated that the proportion of substance used disorder in males more than females, but the severity of addiction is more in females than males.

The mean age of the sample in the study was 15.55 years, the study showed a decrease in the average age of abuse. Such result was close to Helmi (2009) who found that mean age is 17.38 years.

Regarding the social status of parent in the present work the study showed that $52 \%$ of the parents of the cases living together compared to $46 \%$ of tha control, and $32 \%$ of the parent cases was separated compared to $42 \%$ of control, and $10 \%$ of cases had one parent's death compared to $6 \%$ of the control, and $6 \%$ for both control and cases had death of both parents. Brown et al. (2010) found that teens in single-mother families or married stepfamilies are nearly one-and-a-half times as likely, and those in cohabiting stepfamilies are 2.2 times as likely, to smoke and drink as teens in families with two biological married parents.

According to family history of mental illness ,the study found that $92 \%$ of the cases did not have a family history of mental illness compared to $84 \%$ of the control, and that $8 \%$ of the cases have a family history of mental illness compared to $16 \%$ of the control. The study showed that there was no statistical significance in family history of mental illness. Sitnick et al. (2014) found an association between clinical levels of maternal depression and later substance use problems, with children of a clinically depressed mothers being five times more likely to experience alcohol dependence during adolescence than children whose parents are not clinically depressed.

According to family history of addiction, it was found that there were statistically significant differences between the sample and control groups in terms of family history of addiction. It was found that $68 \%$ of the sample cases have a family history of addiction compared to $26 \%$ of the control, and $32 \%$ of the sample cases have no family history of addiction compared to $74 \%$ of control. Becker (2017) stated that there was a link between substance use disorder in adolescents and some parents using narcotics. Nishimura et al. (2013) found a link between parental alcoholism and higher levels of substance use in adolescence.

The results of that study showed that synthetic cannabis (strokes or Voodoo) was the most prevalent narcotic 
substances among adolescent. Johnson et al. (2016) stated that $48.9 \%$ of high school students in the United States use illegal drugs (not including alcohol or tobacco). Wilens et al. (2011) found that the use of more than one substance in the category of adolescents is the rule, not the exception.

According to the results of Mini-Kid Test (diagnostic test). It was found that there were statistically significant differences in the sample for a major depressive episode, dysthymia, posttraumatic stress disorder, attention deficit hyperactivity disorder and generalized anxiety disorder. For the control, there are statistically significant differences for a particular phobia.

There was a relationship between substance use disorder and comorbidity of psychiatric disorders. Salah et al. (2013) stated that substance use disorder (cannabis, tranquilizers and stimulants) was significantly associated with depression. Engelhardt (2017) found that prevalence of anxiety disorders among adolescents with substance use disorder has been reported to increase from $22 \%$ to $27 \%$.Uchida, M., et al., (2018) found that there was a relationship between attention deficit hyperactivity disorder (ADHD) and substance use disorder. Molina et al. (2014) stated that children were diagnosed as ADHD has increased risk of substance use in adolescence.

In that study, a group of adolescents attending outpatient and inpatient departments suffering from substance abuse had a prevalence of psychotic disorders $4.1 \%$ for females and $4.3 \%$ for males. Griffith-Lendering et al. (2013) stated that, during adolescence exposure to psychosis was associated with cannabis. In that study, there was an association between the presence of psychotic symptoms and the use of synthetic cannabis such as (strokes and voodoo), but there were many patient,s who used these substances disappeared psychotic symptoms after a period of withdrawal symptoms and that a small proportion of them about $6 \%$ continued with these symptoms more than one month.

The results of the study showed that there was a direct relationship between the severity of addiction and susceptibility to suicide. Arnlio et al. (2014) stated that there was an association between suicide and not only illicit drugs, but also legal drugs such as tranquilizers and alcohol were closely linked to suicide thinking and attempt. Hakansson et al. (2010) found that suicide attempters are more likely to report binge drinking, intake of illicit drugs, injection of drugs, physical and mental illness, problematic family history, and history of being abused. Franklin et al. (2014) found that alcohol abuse and dependence appeared to be strongly associated with suicide attempt.

On the other hand, Poorolajal et al. (2016) showed that drug abuse/dependence was not significantly associated with suicide attempt. Study showed that impulsivity has arole in suicide not substance abuse.

In spite of the relationship between the severity of addiction and parental treatment there was an inverse relationship between discrimination and methods of treatment of the level according to the image of the father and methods of treatment of the level according to the image of the mother so, 
the more parent were treated properly, the less addictive they were.

There was an inverse relationship between the social status of the parents control and discrimination according to the image of the father and the oscillation according to the image of the mother.

Penjor (2019) found that more disordered parenting patterns were associated with more distress and alcohol abuse in general. Further analyzes to assess the relationship between parenting patterns and alcohol use found no role for moderation, but significant mediation indicated that more dysfunctional parenting patterns were associated with greater distress which in turn was associated with increased alcohol abuse.

\section{CONCLUSION}

The results of the study showed that there was a relationship between the severity of addiction and susceptibility to suicide. There were many psychiatric disorders associated with substance use disorder these disorders are major depression disorder , dysthymia, hyperactivity disorder, attention deficit, generalized anxiety disorder and posttraumatic stress disorder.

\section{REFERENCES}

1. Abd el Maksood A. (2016): Questionnaire of parental attitudes scale. Published by Alanglo Almasreya Library,Cairo,Egypt ,pp. 1-14.

2. Albehairy AA. (2013): Manual of Suicidality probability scale Arabic version the third edition published by Alanglo Almasreya Library,Cairo,Egypt ,pp. 1-8.

3. Arenliu, A., Kelmendi, K., Haskuka, M., Halimi, T and Canhasi, E. (2014): Drug use and reported suicide ideation and attempt among Kosovar adolescents. Journal of Substance Use, 19(5): 358-363.
4. Awaad M, Bishry Z, Hamed A and, Ibrahim, M. (2002): Comparison of the Mini International Neuropsychiatric interview for children (MINIKID) with the schedule for affective disorders and schizophrenia for school aged children present and lifetime version (K-SADs-PL). In an Egyptian sample presenting with childhood disorders. MD Thesis in psychiatry in Ain Shams university library.

5. Becker, S. J., Hernandez, L., Spirito, A. and Conrad, S. (2017): Technology-assisted intervention for parents of adolescents in residential substance use treatment: protocol of an open trial and pilot randomized trial. Addiction Science \& Clinical Practice, 12(1): 205-212.

6. Brown, S. L. and Rinelli, L. N. (2010): Family structure, family processes, and adolescent smoking and drinking. Journal of Research on Adolescence, 20(2): 259-273.

7. Christine B., Cha CB., Franz PJ and M Guzmán E. (2017): Annual Research Review: Suicide among youth-epidemiology,(potential) etiology, and treatment. Journal of Child Psychology and psychiatry, 59(4): 460-482.

8. Engelhardt, E. J. (2017): Self-efficacy, social capital, and the common liability to addiction: Relationships to adolescent choices for addiction treatment (Doctoral dissertation, Boston University. Addiction Research and Theory, 27(5): 429-436.

9. Franklin, J. C., Ribeiro, J. D., Fox, K. R., Bentley, K. H., Kleiman, E. M., Huang and Nock, M. K. (2017): Risk factors for suicidal thoughts and behaviors: a meta-analysis of 50 years of research. Psychological Bulletin, 143(2): 187-188.

10. Glenn, C. R., Franklin, J. C. and Nock, M. K. (2015): Evidence-based psychosocial treatments for self-injurious thoughts and behaviors in youth. Journal of Clinical Child \& Adolescent Psychology, 44(1): 1-29.

11. Griffith-Lendering, M. F., Wigman, J. T., Prince van Leeuwen, A., Huijbregts, S. C., Huizink, A. C., Ormel, J and Vollebergh, W. A. (2013): Cannabis use and vulnerability for psychosis in early adolescencea TRAILS study. Addiction, 108(4): 733-740.

12. Hakansson, A., Bradvik, L., Schlyter, F. and Berglund, M. (2010): Factors associated with the history of attempted suicide: A criminal justice population examined with the Addiction Severity Index (ASI). Crisis: The Journal of Crisis 


\section{ALI ISMAIL ABD EL-RAHMAN et al.,}

Intervention and Suicide Prevention, 31(1): $2010,12-21$

13. Hartwell, K. J., Tolliver, B. K., and Brady, K. T. (2009): Biologic commonalities between mental illness and addiction. Primary Psychiatry, 16(8): 33-38

14. Helmi, Kh. (2009): Fmily related factors as predictors of drug dependence among adolescents and youth in Alexandria, Faculty of Medicine, Ain shams University.

15. Jain, S., Pattanayak, R. D., Bhargava, R.and Dhawan, A. (2016): Early-onset heroin use and its link to conduct disorder: Clinical and management challenges. Journal of Mental Health and Human Behaviour, 21(2): 129-131.

16. Johnson LD, O'Malley PM, Miech RA, Bachman JG and Schulenberg JE (2016): Monitoring the Future national survey results on drug use, 1975-2015: Overview, key findings on adolescent drug use. Ann Arbor, MI: The University of Michigan Institute for Social Research

17. Molina BS, Hinshaw SP, Arnold LE, Swanson JM, Pelham WE, Hechtman L, Hoza B, Epstein JN, Wigal T, Abikoff $\mathrm{HB}$ and Greenhill $\mathrm{LL}$ (2014): Adolescent substance use in the multimodal treatment study of attentiondeficit/hyperactivity disorder (ADHD)(MTA) as a function of childhood ADHD, random assignment to childhood treatments, and subsequent medication. Journal of the American Academy of Child \& Adolescent Psychiatry; 52(3): 250-63.

18. Nishimura, S. T., Hishinuma, E. S. and Goebert, D. (2013): Underage drinking among Asian American and Pacific Islander adolescents. Journal of Ethnicity in Substance Abuse, 12(3): 259-277.

19. Penjor, S., Thorsteinsson, E. B., Price, I and Loi, N. M. (2019): Parenting style, distress, and problematic alcohol use in Bhutan. Cogent Psychology, 6(1): 157-203.
20. Poorolajal, J., Haghtalab, T., Farhadi, M.and Darvishi, N. (2016): Substance use disorder and risk of suicidal ideation, suicide attempt and suicide death: a meta-analysis. Journal of Public Health, 38(3), e282-e291.

21. Salah EM, Yamamah GA, Megahed HS, Salem SE and Khalifa AG (2013): Screening for depressive symptoms and their associated risk factors in adolescent students in South Sinai, Egypt. Life Sci J., 10(3): 433-443.

22. Scherf, K. S., Behrmann, M. and Dahl, R. E. (2012): Facing changes and changing faces in adolescence: a new model for investigating adolescent-specific interactions between pubertal, brain and behavioral development. Developmental Cognitive Neuroscience, 2(2): 199-219.

23. Sheehan DV, Sheehan KH, Shytle RD., Janavs, J., Bannon, Y., Rogers, J. E., and Wilkinson, B. (1990): Reliability and validity of the Mini International Neuropsychiatric Interview for Children and Adolescents (MINI-KID). J Clin Psychiatry; 71(3): 313-326.

24. Sitnick S, Shaw D and Hyde L (2014): Precursors of Adolescent Substance Use from Early Childhood and Early Adolescence: Testing a Developmental Cascade Model. Dev Psychopathol., 26(1): 125-140.

25. Uchida, M., Spencer, T. J., Faraone, S. V. and Biederman, J. (2018): Adult outcomeof ADHD: an overview of results from the MGH longitudinal family studies of pediatrically and psychiatrically referred youth with and without ADHD of both sexes. Journal of Attention Disorders, 22(6): 523534.

26. Wilens, T. E., Martelon, M., Joshi, G., Bateman, C., Fried, R., Petty, C. and Biederman, J. (2011): Does ADHD predict substance-use disorders? A 10-year follow-up study of young adults with ADHD. Journal of the American Academy of Child \& Adolescent Psychiatry, 50(6): 543-553. 
SUICIDALILTY IN A SAMPLE OF EGYPTIAN ADOLESCENTS WITH... 405

\section{الإتتحار في عينة من المراهقيز المصريين مع إضطراب تعاطي المخدرات}

علي إسماعيل عبد الرحمن، عبدالله أحمد عبدالله مكي، إسماعيل محمد صادق، محمود أسامة عبدالهادى يوسف

قسم الطب النفسى، كلية الطب، جامعة الأزهر

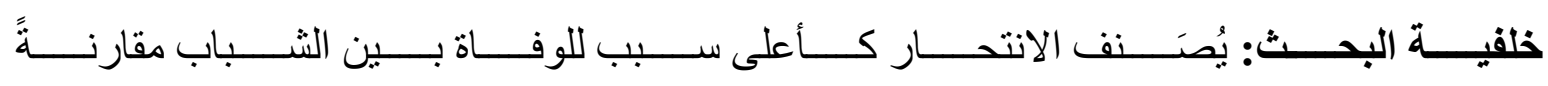

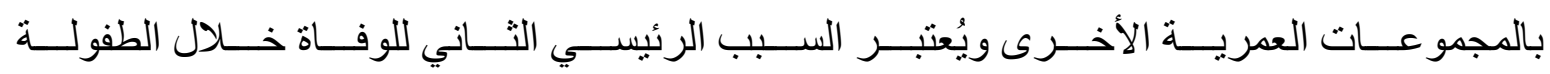
و المر اهقة، في حين أنه السبب الرئيسي العاشر للوفاة بين جميع الفئات العمرية.

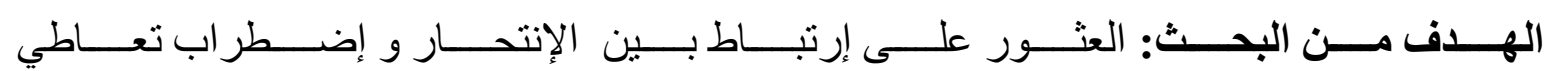
المخدر ات في المر اهقين.

المرضــى وطــرق البحــث: تــم حصـــر المــر اهقين الــذين تتـــراوح أعمــار هم مــن 12-18



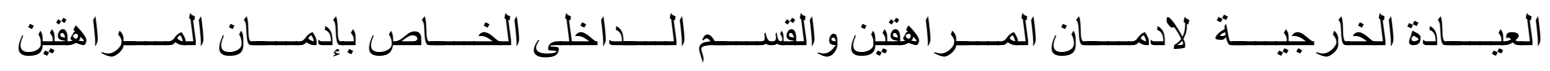

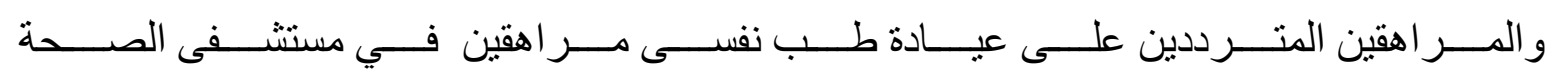

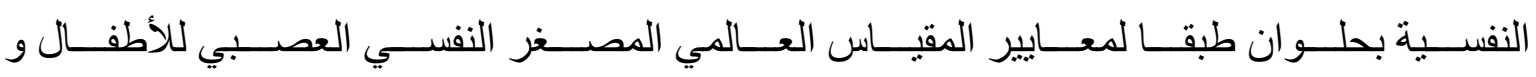
المراهقين (ميني كيد).

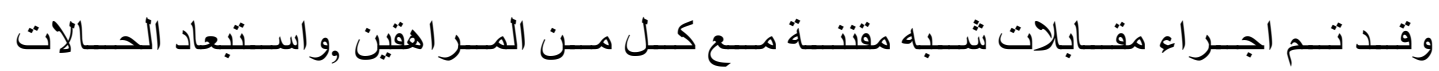





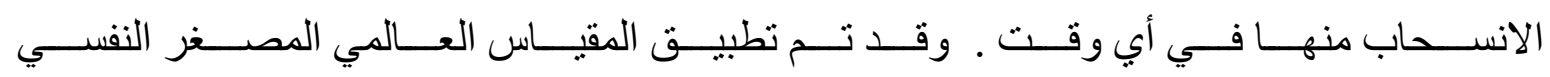

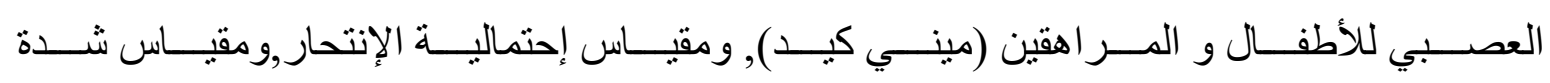
الإدمان للمر اهقين, ومقياس المعاملة الو الدية .

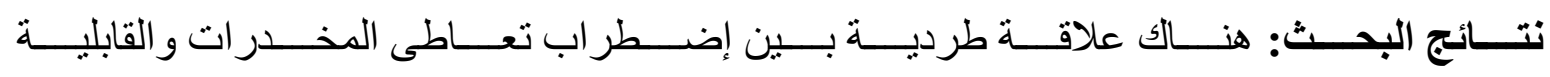

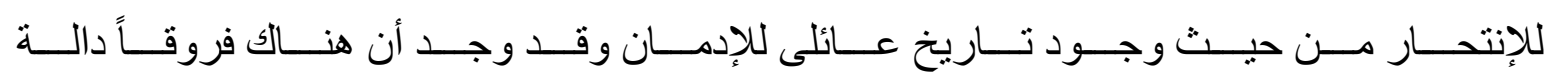








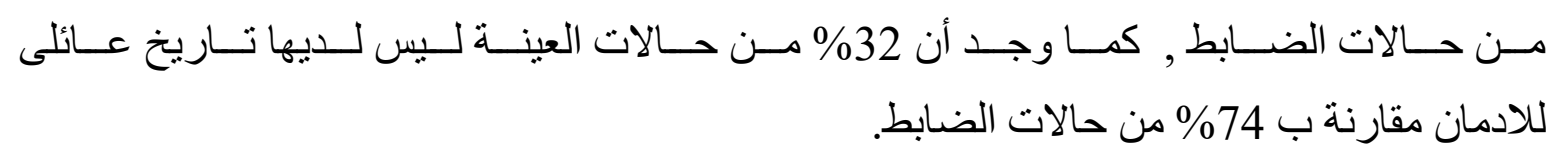

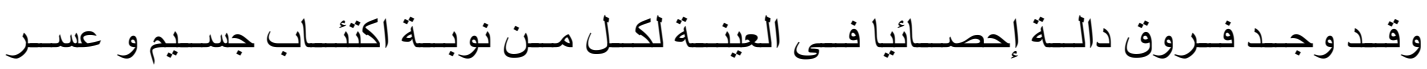

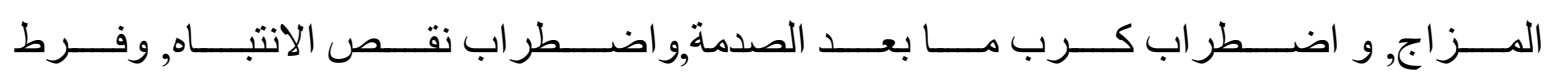

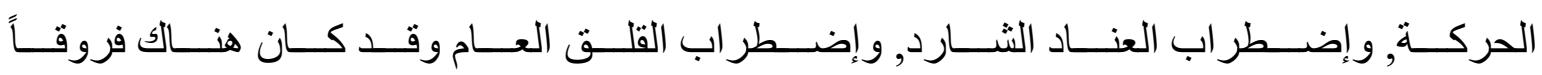
دالة إحصائيا بالنسبة للرهاب خاص.

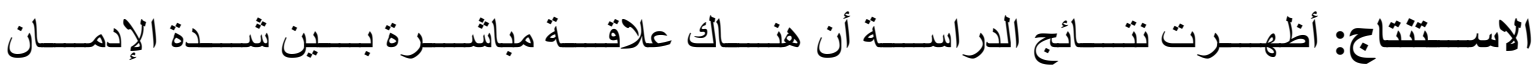

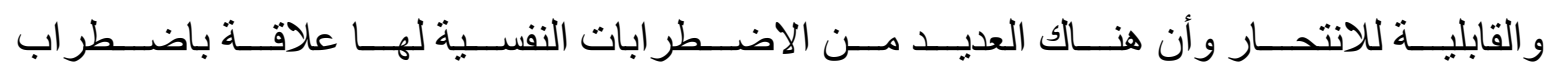
تعاطي المخدرات. 